\title{
German institutes, industry seek to ease genetic engineering laws
}

Munich. The Max Planck Society has joined academic and industrial research groups in pressing the German government to change its gene technology laws - the most restrictive and bureaucratic in Europe. Although the organizations argue that the laws put an unnecessary burden on scientists and delay important experiments that pose no threat to the public, they concede that the political climate is against them and that no changes are likely in the next couple of years.

The problem arose in the autumn of 1989 when the government of Hessen, one of Germany's 16 states, blocked approval of a plant built by Hoechst to produce genetically engineered human insulin. The local ruling in effect prevented any genetic engineering for production purposes in Hessen.

At the time, there was no federal legislation controlling genetic engineering. Within months, however, the government had drawn up and won approval for a law consistent with a 1990 directive on genetic engineering from the European Communities (EC). The legislation is seen as a concession to the environmental Green party in the run-up to the 1991 elections, and critics say that too little thought was given to the scientific principles involved.

Researchers now face repetitive forms and delays in carrying out experiments. They complain that the law fails to make distinctions among experimental work in four safety bands. Experiments in the lowest band, which account for 80 per cent of cases, by definition pose no hazard to humans or the environment. But the federal law requires them to be treated in the same manner as experiments classified as low- and medium-risk: they must be done in certified laboratories after completion of a 30-page document describing any new experimental procedure and questionnaires on each experiment.

The society, Germany's largest independent research organization, would like to eliminate notification and documentation for experiments defined as carrying no risk. At the moment, says Peter Hofschneider, director of the Max Planck Institute for Biochemistry in Martinsried near Munich, it is as if the government required the same safety standards for bicycles as for aeroplanes. The ZKBS, the official body responsible for implementing the law, is not happy sifting through volumes of redundant information, and it has published a list of well-studied organisms and vectors that are exempt from notification.

Hans-Georg Heidrich, safety officer at the Martinsried institute, says that the endless forms contribute nothing to safety. His unit actually ignores those for the lowest safety level and instead keeps relevant and appropriate written records, including those on risk assessment. That practice is acceptable to Bavarian officials but not to the
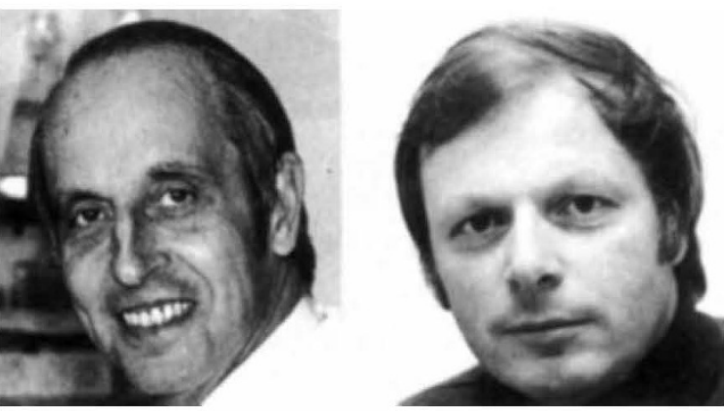

Max Plank's Hofschneider, left, and Heidrich.

Berlin-based pressure group, Genethisches Netzwerk. A spokesman, Wolfgang Lühr, says that biologists should be fully accountable for their experiments at all levels.

The society also wants separate forms for low-risk and medium-risk experiments that would collect more appropriate information and would eliminate the three-month delay now required between submission and approval of applications for no-risk and lowrisk experiments. These delays are often extended for several months by requests for additional information. Max Planck scientists also want to regain the right to ship genetically engineered material to other countries, an important aspect of international collaborations.

Industry has objected to the federal gene law since its inception in July 1990. Dieter Brauer of Hoechst blames some of its flaws on ambiguities in the $1990 \mathrm{EC}$ directive on biotechnology, which is difficult to integrate into national laws. Like academic researchers, industry complains about the bureaucratic obstacles that put German companies at a competitive disadvantage. The last straw has been a regulation allowing research only on small volumes; in Hessen, 'small' is defined as up to $10 \mathrm{l}$. A company whose developmental research requires larger volumes must comply with new, costly and time-consuming requirements before it can scale up.

These problems were acknowledged at a public hearing last February. But lack of confidence that things will change is forcing industrial genetic engineering out of Germany. BASF has built its US $\$ 200$ million research institute for molecular biology in Worcester, Massachusetts. Bayer has decided to expand its pharmaceutical and medical research in the United States rather than at home. The gene law tipped the balance of Boehringer Mannheim's decision to build a large research and production centre in Minneapolis, Minnesota. And Hoechst has moved development of GMC-SF, hirudin and Factor XIII to its subsidiaries in the United States, France and Japan.

Industry has the option of moving out, whereas national institutes do not. As a result, academic researchers are maintaining pressure on the government despite holding out little hope of change before the next election in 1994.

Nevertheless, all sides believe that some tinkering with the rules may lighten the burden. They hope that the federal government may be persuaded to instruct individual states to interpret the law less strictly.

A more lenient approach will not alter the inherent contradictions of a gene law that judges a safe experiment to be unsafe - but it may help to contain the rising tide of bureaucracy. Officials may even be prepared to make some improvements to the weighty forms they distribute; for example, the ZKBS is extending a forthcoming list of exempted organisms and vectors, asking state governments to allow their unreported use.

Alison Abbott

\section{California's money woes hit universities}

Washington. Sixty-two days after it had run out of money, California's state government passed a budget last week that imposes cuts amounting to $\$ 10.7$ billion on state agencies, including a \$224 million (12 per cent) reduction from last year's funding for the nine University of California (UC) campuses. Although UC officials hope that revenue from a proposed tuition fee increase of 24 per cent will avert wholesale cuts, some research programmes are expected to feel the knife as the state looks for new ways to save money. Nearly 2,000 university employers chose a voluntary early retirement programme offered last year, and university officials are concerned that there are few left to do likewise this year. And the cost of operating the university system has risen by 30 per cent since 1988 despite state funding levels that have been flat or worse.

Christopher Anderson 